\title{
Spontaneous pyogenic granuloma on port wine stain: case report
}

\author{
Diah Mira Indramaya $^{\mathrm{a}^{*}}$, Natalia Tanojo ${ }^{\mathrm{a}}$ \\ ${ }^{a}$ Department of Dermatology and Venereology, Faculty of Medicine, Airlangga University / Hospital dr. Soetomo, Jl. Major General \\ Prof. Dr. Moestopo No.6-8, Surabaya, Indonesia. \\ *HP. +62 812-3037-841| e-mail: idiahmira@yahoo.com
}

\begin{abstract}
Introduction: Pyogenic granuloma (PG) is a benign vascular tumor of skin and mucous membranes which more commonly develops following trauma, laser treatment, or pregnancy. Although infrequently, PG may arise spontaneously in richly vascularized area due to arteriovenous anastomoses found in Port Wine Stain (PWS).

Case Presentation: A 44-year old woman presented with a solitary, dome-shaped, $7 \times 7 \mathrm{~mm}$ nodule covered with crusts and scales emerging on sharply demarcated erythematous macule extending from temporal to maxillary part of the left side of her face. The distribution was aligned with the innervation of the second branch of trigeminal nerve. We performed shave biopsy for treatment and followed with $30 \%$ TCA to treat the bleeding. The obtained specimen reveled acanthosis, rete ridges lengthening, and capillary proliferation under histopathology examination, confirming the diagnosis of PG. However, the specimen was not enough to confirm the diagnosis of PWS histologically.

Discussion: The congenital defect in PWS may have increased number arteriovenous anastomoses that lacks capillary bed to deliver blood to surrounding tissue. The decrease in oxygen delivery may induce angiogenesis that may contribute to the development of PG.
\end{abstract}

Keywords: Pyogenic granuloma; port wine stain; shave biopsy

\section{Introduction}

Pyogenic granuloma (PG), known as lobular capillary hemangioma, is a benign vascular tumor of skin and mucous membranes more commonly found in children.(Amerson, Burgin and Shinkai, 2019; MacArthur and Püttgen, 2019; Shruti et al., 2019) PG more commonly develop following trauma, laser treatment, or pregnancy.(Chen et al., 2011; Shruti et al., 2019) Although infrequently, PG may arise spontaneously in richly vascularized area due to arteriovenous anastomoses.(Shruti et al., 2019) PWS is a congenital vascular of neural malformation and consist of ectasia of venules in the upper dermis and, speculatively, arteriovenous anastomoses.(Chen et al., 2011) Therefore, PWS may be underreported predilection factor of PG. Here we reported a case of spontaneous PG arising within PWS without prior history of trauma, laser treatment, nor pregnancy in adult woman.

\section{Case Presentation}

A 44-year old woman presented with a lesion on her forehead that rapidly grow within 2 months within a congenital, diffuse red patch extending from temple to cheek. The growth was non-pruritic with occasional episodic spontaneous bleeding. She reported frequent squeezing of the growth when it was smaller and the growth seemed to increase in size following the action. She denied history of manipulating the site of growth before the occurrence. Similar growths arose on her gum during her first and second pregnancy, approximately 
15 and 21 years prior.

Upon physical examination, we found a solitary, dome-shaped, $7 \times 7 \mathrm{~mm}$ nodule covered with crusts and scales emerging on sharply demarcated erythematous macule extending from temporal to maxillary part of the left side of her face. The distribution was aligned with the innervation of the second branch of trigeminal nerve. We performed shave biopsy for treatment and followed with 30\% TCA to treat the bleeding. The obtained specimen reveled acanthosis, rete ridges lengthening, and capillary proliferation under histopathology examination, confirming the diagnosis of PG (Figure 2). However, the specimen was not enough to confirm the diagnosis of PWS histologically. Lesion completely healed within 7 days of treatment.
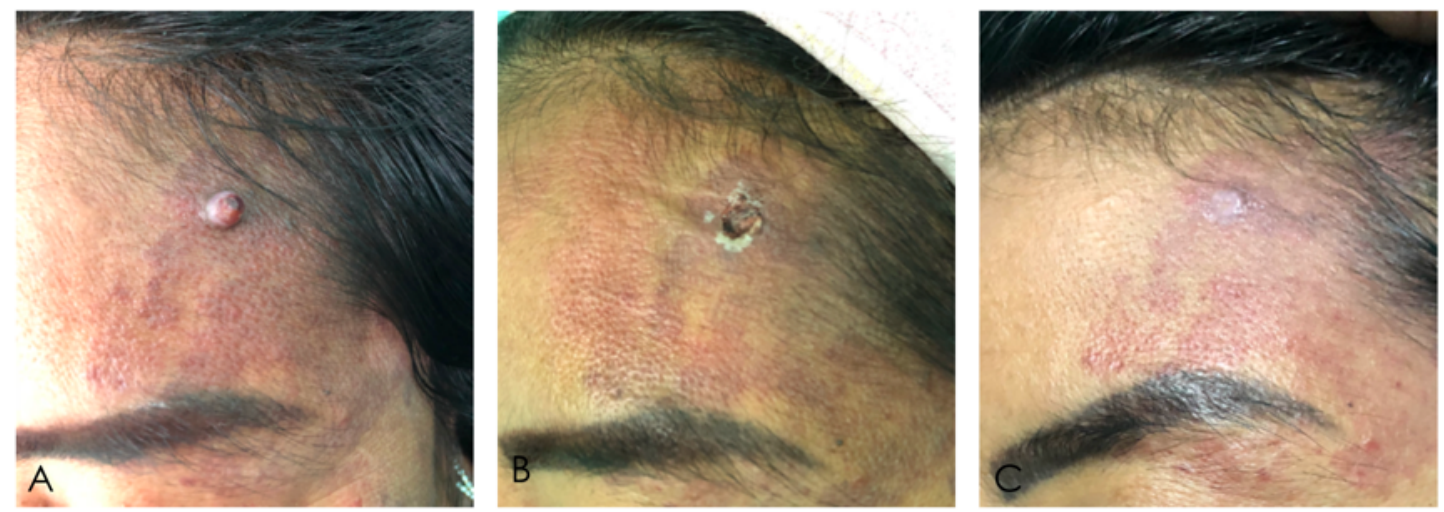

Figure 1 Clinical features of the patient at first presentation (A), after shaving biopsy (B), and 1 week after (C).
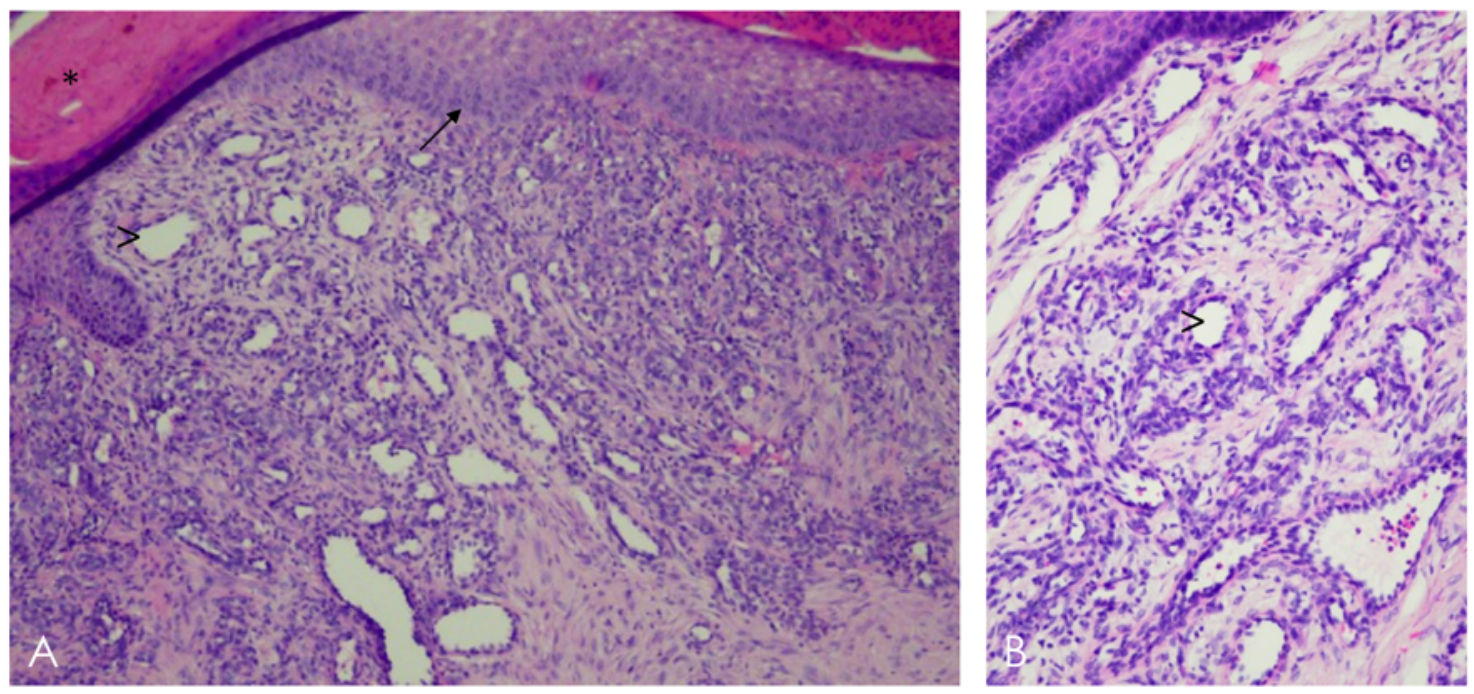

Figure 2 Histopathological picture at (A) 40x and (B) 100x magnification. There is acanthosis (*), capillaries $(>)$, and rete ridges lengthening (arrow). 


\section{Discussion}

PG is a mass of capillaries and venules with immature endothelial cells proliferation amidst an edematous stroma.(Chen et al., 2011) Understanding the histology of PG explains why the lesion may spontaneously arise on arteriovenous anastomoses in vascular-rich areas like fingers, hands, lips, tongue, and face, although it is even more likely to occur following lesions manipulations, such as rubbing of a shirt collar, cryotherapy, or lasers.(Rodins et al., 2011; Shruti et al., 2019)

Cutaneous PG is more likely to develop in children, while oral PG in pregnant women.(Rodins et al., 2011) Reports found that PG may also arise within pre-existing vascular abnormalities, such as PWS.(Chen et al., 2011) The congenital defect in PWS may have increased number arteriovenous anastomoses that lacks capillary bed to deliver blood to surrounding tissue. The decrease in oxygen delivery may induce angiogenesis that may contribute to the development of PG.(Chen et al., 2011) The hypothesis may explain the finding of cutaneous PG on an adult, non-pregnant woman. Statistically, nodules arising within PWS are more prone to occur in the area of the face innervated by the second branch trigeminal nerve, which confirmed the result found in this case.(Chen et al., 2011)

Shave excision is one of the treatments that allow for histological confirmation and hence provide diagnosis certainty.(Rodins et al., 2011) However, the lack of skin depth hindered us from confirming the diagnosis of PWS in our case. An excisional biopsy should be considered in future case for better histological confirmation.

\section{Acknowledgements}

I would like express my gratitude to the Dermatology and Venereology department of Airlangga University for the opportunity and also my beloved family and friends for their endless support and encouragement.

\section{References}

Amerson, E. H., Burgin, S. and Shinkai, K. (2019) 'Fundamentals of clinical dermatology: morphology and special clinical considerations', in Kang, S. et al. (eds) Fitzpatrick’s Dermatology in General Medicine. 9th edn. New York: McGrawHill, p. 34.

Chen, D. et al. (2011) 'Nodules arising within port-wine stains: a clinicopathologic study of 31 cases.', The American Journal of dermatopathology. United States, 33(2), pp. 144-151. doi: 10.1097/DAD.0b013e3181e169f5.

MacArthur, K. M. and Püttgen, K. (2019) 'Vascular Tumors', in Kang, S. et al. (eds) Fitzpatrick's Dermatology in General Medicine. 9th edn. New York: McGrawHill, pp. 2063-4.

Rodins, K. et al. (2011) 'Pyogenic granuloma, port-wine stain and pregnancy.', The Australasian journal of dermatology. Australia, 52(4), pp. e8-e10. doi: 10.1111/j.1440-0960.2010.00680.x.

Shruti, S. et al. (2019) 'Recurrent pyogenic granuloma over nevus flammeus.', Indian journal of dermatology, venereology and leprology. India, p. 236. doi: 10.4103/ijdvl.IJDVL_80_17. 